\title{
Niñas y niños soldados, el Derecho Internacional Público y Naciones Unidas
}

\author{
Child soldier, International Public Law and United Nations
}

María Florencia Guzmán ${ }^{1}$

\section{Resumen}

El reclutamiento de niños y niñas soldados es una problemática que continúa vigente y que mantiene en vilo a toda la comunidad internacional. Es por eso, que el presente trabajo expone cuáles son los principales instrumentos del Derecho Internacional Público que tienen como finalidad proteger a las niñas y niños, prohibiendo su participación en los conflictos armados. A su vez, se describe cuál ha sido el rol desempeñado por Naciones Unidas junto a UNICEF para poder frenar esta problemática. A fin de ejemplificar esta situación, se utilizaron los casos de Siria, Sudán del Sur y República Democrática del Congo. Luego se invita al debate de cuál debe ser el camino a seguir, tanto por Naciones Unidas junto a UNICEF y los Instrumentos del Derecho Internacional Público para ponerle fin a esta problemática.

Palabras clave: Niños y niñas soldados, Derecho Internacional Público, Organismos Internacionales

\section{Abstract}

Child soldiers' recruitment is an ongoing problem that keeps the entire international community on edge. For this reason, the present work exposed which are the main instruments of Public International Law that are intended to protect children prohibiting their participation in armed conflicts. In turn, a description is made of the role played by both the United Nations and UNICEF in order to curb this problem. In order to exemplify this situation, the cases of Syria, South Sudan and the Democratic Republic of the Congo were used. Then, it invites to debate what should be the way followed by both the United Nations and the Instruments of Public International Law to put an end to this problem.

Keywords: Child soldier, International Public Law, International Organizations.

Recibido: 31 de marzo de 2020 Aceptado: 30 de junio de 2020 Publicado: 10 de julio de 2020

${ }^{1}$ Licenciada en Relaciones Internacionales, Universidad Nacional de Rosario (UNR) Rosario, Argentina.

Correo electrónico: florguzmanc2@gmail.com 


\section{Introducción}

Los niños y niñas son grandes víctimas de los conflictos armados, ya que, debido a su vulnerabilidad, distintos grupos armados, los reclutan con el objetivo de hacerlos partícipes en sus actividades, cumpliendo el rol de soldados. Por niña y niño soldado los Principios de Ciudad del $\mathrm{Cabo}^{2}$ entienden lo siguiente:

Un niño soldado es cualquier persona menor de 18 años que forma parte de cualquier tipo de fuerza armada regular o irregular en cualquier capacidad, inclusive, pero no sólo, como cocinero, porteador, mensajero, y cualquiera que acompaña a estos grupos, excepto los familiares. La definición incluye niñas reclutadas para realizar actividades sexuales y contraer matrimonios por la fuerza (UNICEF, 2020, p.1).

Esta problemática continúa existiendo en la actualidad, pese al esfuerzo de la comunidad internacional por erradicarla. Si bien es difícil calcular un número exacto, las estimaciones denotan un total de 300.000 niños soldados alrededor del mundo, sobre todos en guerrillas y conflictos dentro de sus respectivos países, ya sea bajo el mando del ejército oficial o grupos subversivos (UNICEF España, 2020).

Se parte del supuesto de que, en los últimos años, Naciones Unidas y su organismo especializado el Fondo Internacional de Emergencia de las Naciones Unidas para la Infancia (UNICEF), a través de la aprobación de diferentes resoluciones, desarrollaron tareas en función de prevenir esta situación y contribuir en la reinserción de las víctimas en sociedad. Esto se pudo lograr gracias al respaldo de los instrumentos del Derecho Internacional Público que resguardan los derechos del niño y la niña.

Es por ello, que los objetivos del presente artículo consisten en exponer cuáles son los instrumentos jurídicos más relevantes que protegen a los niños y las niñas frente a su reclutamiento en conflictos armados, y describir el desempeño de Naciones Unidas junto a UNICEF, ante tal violación de los derechos del niño y la niña.

En consecuencia, tres países serán tomados como referencia de estudio de caso. El común denominador entre los mismos es que, en las últimas décadas, reclutaron niños y niñas sistemáticamente para hacerlos participes en sus conflictos internos. Estos países son: Sudán del Sur, República Democrática del Congo y Siria.

\footnotetext{
2 En abril de 1997, UNICEF junto con diferentes Organizaciones no Gubernamentales, llevan a cabo un simposio relacionado con la temática de niños soldados, en consonancia con el trabajo que venía realizando Naciones Unidas en esta área. El resultado de estas reuniones fue un documento titulado "Principios de Ciudad del Cabo sobre la prevención del reclutamiento de niños en las fuerzas armadas y desmovilización y reintegración social de los niños soldados en África" (UNICEF, 2007, p.4).
} 
Para finalizar, se analizará si los trabajos y esfuerzos realizados por parte de la comunidad internacional, específicamente tanto por el Derecho Internacional Público como por los Organismos Internacionales anteriormente especificados, han dado resultados o han aportado alguna mejoría en los últimos años, y cuál debe ser el curso a seguir por los mismos, para que en algún futuro cercano se le pueda poner fin a esta problemática.

\section{El Derecho Internacional Público y la protección a la infancia}

Vastos esfuerzos se realizaron en el ámbito jurídico internacional a fin de proteger a los niños y las niñas en situaciones de conflictos armados. Tal es así, que en las últimas décadas, diversos gobiernos nacionales y organismos internacionales han realizado declaraciones, firmado convenciones, tratados, protocolos y promulgado otros textos jurídicos de carácter internacional para garantizar los derechos de los niños y las niñas en las peores circunstancias, como lo es el conflicto armado.

Si bien en el año 1924 Sociedad de Naciones aprobó la Declaración de Ginebra sobre los derechos de la niñez, la misma carecía de fuerza vinculante para los Estados. Diez años después, la Asamblea General aprobó el nuevo texto de la Declaración, pero la misma continuó siendo no vinculante, es decir, de carácter no obligatorio. "No obstante, la Declaración de Ginebra sigue siendo el primer texto internacional en la historia de los Derechos Humanos que específicamente trata sobre los Derechos de la Niñez" (Humanium, 2017, p.1).

Al finalizar la Segunda Guerra Mundial se tornó de vital importancia la revisión del derecho internacional humanitario, debido a las atrocidades cometidas en dicha guerra. Es así como el Comité Internacional de la Cruz Roja (CICR) realizó grandes esfuerzos en elaborar disposiciones especiales para protección de los niños y las niñas en situaciones de conflictos armados.

Si bien el trabajo dio por resultado la firma de 4 Convenios, los derechos de los niños y las niñas en situaciones de guerra se ven reflejados en el IV Convenio de Ginebra de 1949 relativo al amparo de las personas civiles en tiempo de guerra, en el que se toma a los niños y las niñas como parte de la población civil, y por ende, se benefician de este Convenio, así como también poseen una protección especial en su favor, incluida en nada menos que diecisiete de sus disposiciones (Plattner, 1984, p.1).

Como parte del progreso obtenido en el derecho humanitario, en 1977 se aprobaron los dos Protocolos Adicionales a los Convenios de Ginebra de 1949. En estos, por primera vez en la historia aparece la protección de niños y niñas en 
conflictos armados. Esta medida se puede observar en el artículo 77 - Protección de los niños, del Protocolo I:

Las Partes en conflicto tomarán todas las medidas posibles para que los niños menores de quince años no participen directamente en las hostilidades, especialmente absteniéndose de reclutarlos para sus fuerzas armadas. Al reclutar personas de más de quince años pero menores de dieciocho años, las Partes en conflicto procurarán alistar en primer lugar a los de más edad (Comité Internacional de la Cruz Roja, 2020, p.50).

La protección de los derechos de la niñez fue reafirmada en la Convención sobre los Derechos del niño, aprobada por Naciones Unidas el 20 de noviembre de 1989, cuyo carácter es casi universal.

De todas formas, si bien en el artículo 1 de dicha Convención "se entiende por niño todo ser humano menor de dieciocho años de edad, salvo que, en virtud de la ley que le sea aplicable, haya alcanzado antes la mayoría de edad" (UNICEF, 2015, p.8), en lo que respecta a los menores y la participación en conflictos, se retoman las normas del derecho internacional humanitario, y por ende se establece en quince años la edad mínima necesaria para el reclutamiento en conflictos armados, a pesar de los esfuerzos realizados durante las negociaciones por diferentes gobiernos y organizaciones a fin de aumentar la minoría de edad.

Esto se puede observar en el artículo 38.3 de la Convención sobre los Derechos del Niño:

Los Estados Partes se abstendrán de reclutar en las fuerzas armadas a las personas que no hayan cumplido los 15 años de edad. Si reclutan personas que hayan cumplido 15 años, pero que sean menores de 18, los Estados Partes procurarán dar prioridad a los de más edad (UNICEF, 2015, p.24).

Por otro lado, como consecuencia de los cambios en la naturaleza de las contiendas durante la Posguerra Fría aumentaron considerablemente el número de muertes entre la población civil. A su vez, la facilidad de acceso a armas ligeras, contribuyó al mayor reclutamiento de menores en dichos conflictos. Como resultado de esta situación, los promotores que abogaban por la defensa de los derechos de la niñez, años después, continuaban en su cometido por aumentar la edad del reclutamiento en conflictos armados desde los 15 años a 18 años por medio de la creación de un nuevo tratado internacional. 
Sin embargo, debido al fuerte apoyo que recibió la Convención sobre los Derechos del Niño, se pensó en redactar un Protocolo Facultativo de la Convención que hiciera hincapié específicamente en la participación de los niños y las niñas en los conflictos armados, en lugar de crear uno nuevo.

A partir de esto, el 25 de mayo del 2000, la Asamblea General de las Naciones Unidas aprobó de forma oficial el Protocolo Facultativo, el cual entró en vigor en febrero del 2002. Al día de hoy, 166 países lo han ratificado, 18 no lo han firmado o ratificado y 13 miembros de Naciones Unidas lo han firmado, pero no ratificado (Oficina del Alto Comisionado para los Derechos Humanos, 2017).

Este instrumento jurídico internacional refuerza la protección debida a los niños y las niñas en caso de conflicto armado aumentando la edad de reclutamiento a $18 \mathrm{y}$ enmendando así la anomalía que se había querido ya mejorar durante la negociación de la Convención sobre los derechos del niño (Oficina del Representante Especial del Secretario General para los Niños y los Conflictos Armados, 2017).

Este Protocolo, cuyo artículo 1 expone: "Los Estados Partes adoptarán todas las medidas posibles para que ningún miembro de sus fuerzas armadas menor de 18 años participe directamente en hostilidades" (Oficina del Alto Comisionado para los Derechos Humanos, 2017), es entendido como un hito en esta campaña de lucha contra el reclutamiento de niños y niñas en conflictos armados.

No obstante, se lamenta que la edad mínima de reclutamiento voluntario en las fuerzas gubernamentales no haya podido fijarse en dieciocho años como lo ha sido para el reclutamiento obligatorio. Esto se encuentra detallado en su artículo 3, inciso 3:

Los Estados Partes que permitan el reclutamiento voluntario en sus fuerzas armadas nacionales de menores de 18 años establecerán medidas de salvaguardia que garanticen, como mínimo, que:

a) Ese reclutamiento sea auténticamente voluntario;

b) Ese reclutamiento se realice con el consentimiento informado de los padres o de quienes tengan la custodia legal;

c) Esos menores estén plenamente informados de los deberes que supone ese servicio militar;

d) Esos menores presenten pruebas fiables de su edad antes de ser aceptados en el servicio militar nacional (Oficina del Alto Comisionado para los Derechos Humanos, 2017).

Además, resulta interesante destacar lo expresado por Graça Machel en su informe "Las repercusiones de los conflictos armados sobre los niños", quien remarcó el 
hecho de que los gobiernos no estén sometidos a las mismas normas estrictas que se aplican a los grupos no estatales, podría menoscabar las intenciones del Protocolo Facultativo, lo cual puede considerarse un vacío dentro del mismo, al igual que la falta de definición precisa sobre niños y niñas soldados.

Esto mismo se reitera al no haber una definición concreta de "participación directa en las hostilidades", y no explicitar la diferencia entre participación "directa" e "indirecta", a la hora en que se fija la edad mínima. En consecuencia, ello da lugar a diferentes actividades incluidas en la participación indirecta que van desde tareas de reconocimiento, espionaje, sabotaje hasta la participación como blancos ficticios, correos, porteadores, cocineros o asistentes en puestos de vigilancia militares, e incluso la utilización de niñas para realizar actividades sexuales o para contraer matrimonios por la fuerza.

En los Principios de Ciudad del Cabo, adoptados en 1997 en el "Simposio sobre la prevención del reclutamiento de niños en las fuerzas armadas, la desmovilización y reintegración social de niños soldados en África” (UNICEF, 2007, p.4), se puede observar un avance en la concepción de niños y niñas soldados al adoptarse una definición ampliada de lo que representa y la participación de estos en hostilidades, a fin de que la protección abarque a la mayor cantidad posible de niños y niñas, y asegurar su inclusión en los programas de desmovilización y reintegración ${ }^{3}$.

Por otra parte, con el fin de apoyar y reforzar lo establecido por la Convención sobre los Derechos del Niño, otros instrumentos jurídicos se han aprobado y entrado en vigor en los últimos años. Entre los más significativos se encuentran: la Carta Africana sobre los Derechos y el Bienestar de la Infancia, la Convención número 182 de la Organización Internacional del Trabajo sobre la Prohibición y Acción Inmediata para la Eliminación de las Peores Formas de Trabajo Infantil y el Estatuto de Roma que da inicio a la Corte Penal Internacional.

Con respecto al primer instrumento, en el año 1979, durante la decimosexta sesión ordinaria de la Organización para la Unidad Africana, los Estados partes de la misma reconocieron la necesidad de adoptar medidas que tengan como fin la protección de los derechos de los niños y las niñas en el continente africano. Esto sirvió de base para que una década más tarde, el 11 de julio de 1990, se apruebe la Carta Africana sobre los Derechos y el Bienestar de la Infancia, entrando en vigor el 29 de noviembre de 1999 (ACNUR, 2017).

La misma concibe que los niños y las niñas son aquellas personas menores de 18, prohibiendo firmemente su participación en conflictos armados como soldados. Esto se encuentra textualmente expresado en sus siguientes capítulos:

\footnotetext{
${ }^{3}$ La definición de niño soldado que otorgan los Principios de Ciudad del Cabo ya fue dada en párrafos anteriores.
} 
Artículo 1. Obligaciones de los Estados Parte... Cualquier costumbre, tradición, práctica religiosa o cultural que sea incompatible con los derechos, deberes y obligaciones contenidas en la presente Carta será rechazada en lo que sea incompatible con los mismos.

Art. 2. Definición de niño. A los efectos de la presente Carta, se entenderá por niño todo ser humano menor de dieciocho años.

Art. 22. Conflictos armados. Los Estados Parte en la presente Carta adoptarán todas las medidas necesarias para garantizar que ningún niño tome parte directamente en las hostilidades y, en especial, se abstendrán de reclutar a algún niño (ACNUR, 2017).

En cuanto al convenio número 182 sobre la Prohibición y Acción Inmediata para la Eliminación de las Peores Formas de Trabajo Infantil elaborado por la Organización Internacional del Trabajo, el mismo fue aprobado en junio de 1999 y entró en vigor en noviembre del año 2000 (International Labour Organization, 2017).

Este Convenio define como niños y niñas a todas aquellas personas menores de 18 años; entiende que su reclutamiento para conflictos armados es una de las peores formas de trabajo infantil, solicitando que se pongan en marcha programas de acción para impedir que participen como soldados en las hostilidades y se adopten las medidas necesarias para que esto no continúe sucediendo (dentro de estas medidas se encuentra la opción de sanciones penales o procedimientos de tal magnitud, si así el Estado lo desea). En los siguientes artículos del convenio número 182 sobre la Prohibición y Acción Inmediata para la Eliminación de las Peores Formas de Trabajo Infantil se puede observar lo mencionado recientemente:

Artículo 2. A los efectos del presente Convenio, el término "niño/niña" designa a toda persona menor de 18 años.

Artículo 3 A los efectos del presente Convenio, la expresión "las peores formas de trabajo infantil" abarca: ...(c) la utilización, el reclutamiento o la oferta de niños para la realización de actividades ilícitas, en particular la producción y el tráfico de estupefacientes, tal como se definen en los tratados internacionales pertinentes, ... (International Labour Organization, 2017).

Por último, uno de los instrumentos jurídicos internacionales que se logró concretar en los últimos años y da apoyo concreto a las normas del Protocolo Facultativo sobre la Participación de los Niños en los Conflictos Armados es el Estatuto de Roma. 
El mismo fue aprobado en Roma el 17 de julio de 1998 por la Conferencia Diplomática de Plenipotenciarios de las Naciones Unidas que tenía como fin establecer la Corte Penal Internacional. Puede considerarse como un documento histórico en la campaña contra la utilización de los niños y las niñas en los conflictos armados.

Allí se define como crimen de guerra, entre otros actos, reclutar a niños y niñas menores de 15 años para su posterior participación en hostilidades, tanto internacionales como de nivel nacional. Esto se observa en su artículo 8 - Crímenes de Guerra: "Reclutar o alistar a niños menores de 15 años en las fuerzas armadas nacionales o utilizarlos para participar activamente en las hostilidades" (United Nations, 2020, p.8).

No obstante, el Estatuto del Tribunal para Sierra Leona es considerado un predecesor al Estatuto de Roma. Lo trascendente de dicho Tribunal es su alegación de que "resulta poco probable que un niño o una niña tengan la 'mayor responsabilidad' en la cadena de mando de un grupo armado" (Hinestroza-Arenas, 2008, p.55). Además, el "artículo 7 establece por su parte que, aquellos individuos que en el momento del crimen alegado eran menores de 15 años no serán competencia de la Corte" (Hinestroza-Arenas, 2008, p. 55). Y, como hecho de gran trascendencia, el Tribunal concluyó que el reclutamiento de niñas y niños constituye un crimen de guerra en el marco del derecho internacional.

\section{El rol decisivo de Naciones Unidas y UNICEF frente a esta problemática}

Naciones Unidas junto a su agencia UNICEF, tienen una función fundamental en la comunidad internacional respecto a esta temática, ya que se encuentran inmersos en las diferentes etapas que esta problemática contiene. Primero, procuran concientizar a la sociedad acerca del reclutamiento de niños y niñas, a su vez, ejecutan distintos programas y planes para poder rescatar a aquellos que se encuentran participando en conflictos, y también cumplen un rol importante a la hora de reinsertar en la sociedad a los niños y las niñas que hayan sido partícipes en las hostilidades.

A partir de la presentación del informe redactado en 1996 por la señora Graça Machel, experta designada por el Secretario General de Naciones Unidas, la temática de niños y niñas soldados cobró gran relevancia, dado que, no solo vuelve a promocionar y concientizar a nivel mundial sobre esta cuestión, sino que también sentó las bases para la elaboración de los Planes de Acción de Naciones Unidas y UNICEF (UNICEF España, 2020).

Con la presentación de este informe, los intereses de proteger la infancia, especialmente a las niñas y los niños soldados, fueron poco a poco incluidos en 
Naciones Unidas, implicando un gran avance en la solución de esta problemática. Un importante ejemplo de esto, es el nombramiento por parte de la Asamblea General en 1997 de un Representante Especial del Secretario General para los niños y las niñas en conflictos armados (Naciones Unidas, 2020).

Este Representante Especial, concientiza y promueve la aplicación de normas internacionales para proteger a los niños y las niñas en guerra, y, desde el año 2005 por medio de la resolución 1612 del Consejo de Seguridad, junto a UNICEF, apoya los mecanismos de supervisión, desmovilización y compromiso de no reclutamiento, además de la presentación de informes para mostrar los avances realizados por cada país (UNICEF, 2020).

Otro de los progresos logrados gracias a la Presentación del Estudio Machel se plasmó en el Consejo de Seguridad, debido a que, desde 1999, el reclutamiento de menores es un asunto temático importante para este órgano, emitiendo sus dos primeras resoluciones sobre esta cuestión posteriormente al informe. La primera, la resolución 1261 del año 1999, condena el reclutamiento y establece que la protección de la niñez es una cuestión de paz y seguridad más allá de una cuestión humanitaria. A partir de esta resolución comienzan a realizarse los informes de control. La segunda resolución fue la 1314 del año 2000, que insta a los Estados miembros a firmar y ratificar la Convención sobre los Derechos del Niño relativo a la participación de menores de edad en conflictos armados (Naciones Unidas, 2020). El Consejo de Seguridad también aprobó en el año 2001 la resolución 1379, requerida por el Secretario General, la cual fue para ese momento muy novedosa, ya que incluía la presentación de listas nombrando a los culpables del reclutamiento de niños y niñas en conflictos armados. La primera de estas fue publicada en el año $2003^{4}$ (Naciones Unidas, 2020).

Diez años después de la presentación del Informe Machel, en el año 2007, se presentó ante la Asamblea General de Naciones Unidas, un examen estratégico coordinado por UNICEF. Este es conocido por ser la segunda parte del Estudio de 1996, y su objetivo es la realización de un balance en los progresos obtenidos desde la publicación del primer Informe respecto al reclutamiento de niños y niñas en conflictos armados. También presenta los efectos cambiantes del conflicto, ya que no son las mismas condiciones que una década atrás, como por ejemplo el uso de armas ligeras. Y, por último, demuestra los objetivos que se alcanzaron y cumplieron desde la primera publicación, como lo son la elaboración de normas en

\footnotetext{
${ }^{4}$ Los países y grupos armados culpables solo serán sacado de esta lista una vez que Naciones Unidas certifique que hayan cumplido con el Plan de Acción correspondiente y no continúe utilizando niños como soldados (Unicef, 2004, p.11).
} 
el nivel jurídico internacional para esta problemática, o la participación y el involucramiento de la Asamblea General para hacerle frente (UNICEF, 2009).

Por otro lado, UNICEF lanza anualmente un Plan de Acción con el fin de dar solución a diferentes situaciones que vulneran los Derechos de la niñez, siendo una de estas, la abordada por el presente trabajo, es decir, su reclutamiento para la participación en conflictos armados.

Este Plan consiste en una serie de medidas a seguir y de diferentes evaluaciones para facilitar su puesta en marcha. Además, cuenta con la realización de exámenes periódicos y la presentación de informes con la recopilación de información en los países en cuestión, a fin de poder cerciorarse de que los objetivos de cada plan establecido se cumplan. Cabe destacar que estos deben respetar tanto la legislación nacional del país con el cual se está trabajando, como la Declaración Universal de los Derechos del Niño.

Esta recopilación de información y puesta en marcha de Planes de Acción, para su posterior evaluación, corresponde según la resolución 1539 del Consejo de Seguridad del año 2004, a los equipos de Naciones Unidas en los conflictos armados, bajo dirección de los Representantes del Secretario General.

Con los datos obtenidos, el Representante Especial del Secretario General para niños y niñas en conflictos armados, junto a un equipo de trabajo dedicado a esta temática, realizan los informes en la Sede de Naciones Unidas y luego los envían al Consejo de Seguridad, la Asamblea General, la Corte Penal Internacional, Gobiernos Nacionales, Organismos Regionales, ONGs y Organismos de la Sociedad Civil de relevancia.

En cuanto a los Planes de Acción, como lo explica claramente UNICEF, son un acuerdo o plan que tiene como objetivo principal finalizar con el reclutamiento y utilización de menores en conflictos armados, se encontrarán, por ejemplo, algunas de las siguientes medidas (Naciones Unidas, 2020):

- Tipificar este crimen para poder detener el reclutamiento de niños y niñas en conflictos armados, y en cierta medida aportar para la prevención del mismo.

- Llevar a juicio a aquellas personas culpables de utilizar menores de edad en sus filas, luego de haber realizado una minuciosa investigación.

- Liberar a los menores que fueron identificados luchando dentro de los bandos que se encuentran en conflicto.

- Asegurar que los especialistas encargados de proteger a los niños y niñas, y, por ende, sus respectivos derechos, puedan tener una libre disposición y 
acceso a campamentos y bases militares, para cerciorarse de este modo, que no haya menores en dichas filas.

- Contar con planes y programas para la liberación de los niños y niñas soldados, y su posterior reingreso a la sociedad.

- Verificar la edad de las personas al momento de reclutarlas, utilizando las respectivas partidas de nacimiento, y a su vez, de manera complementaria para el mediano plazo, fomentar las inscripciones y los registros al momento del nacimiento.

- Realizar campañas a nivel nacional para prevenir acerca del reclutamiento de menores de edad en conflictos armados.

A su vez, UNICEF cuenta con diferentes planes y estrategias para llevar a cabo al momento en que los grupos armados ceden frente a la petición de liberar niños y niñas. Propone junto a un equipo de profesionales y voluntarios de todo el mundo una serie de "pasos" para cumplir una vez que los menores fueron rescatados de la tarea de niño y niña soldado. Las tareas y procedimientos generales que tiene como fin llevar a cabo son (UNICEF, 2020):

- Desmovilización $\rightarrow$ esta tarea es la que cumple el objetivo de liberar a la mayor cantidad posible de niños y niñas que fueron víctimas del reclutamiento forzoso o voluntario. Como se explica en el capítulo número 2 , así sea que el menor ingrese de manera voluntaria para combatir junto a grupos armados, es considerado de igual forma como una violación al Protocolo Facultativo de la Convención sobre los Derechos del Niño y un crimen de guerra, según el Estatuto de la Corte Penal Internacional.

Una vez rescatados los menores y bajo la tutela de UNICEF, permanecen un tiempo en un centro de tránsito donde reciben ayuda de distintos profesionales de diferentes áreas especializadas, principalmente de la salud, psicosocial y jurídica.

- Desarme $\rightarrow$ aquí UNICEF tiene como objetivo eliminar la mayor cantidad posible de armas de fuego que estén siendo utilizadas por los grupos armados en cuestión y en muchos casos también, que sean usadas en la sociedad civil. De esta manera, se aseguran de que no tengan las herramientas necesarias (armas de fuego) para reiniciar el conflicto armado, y en el peor de los casos, cerciorarse de que no tengan los elementos de guerra para reclutar niños y niñas para luego enseñarles cómo utilizarlos para el combate.

- Reintegración $\rightarrow$ bajo esta tarea, el programa de Naciones Unidas, junto a su equipo de profesionales y voluntarios, dan asistencia a aquellos adolescentes 
que hayan sido rescatados de los grupos armados. Los mismos reciben la formación profesional que claramente no recibieron mientras eran retenidos como niños y niñas soldados, y muchas veces también le otorgan la ayuda y herramientas necesarias para poder iniciar sus propios negocios y micro emprendimientos.

- Reunificación familiar $\rightarrow$ para el cumplimiento de este objetivo, se trata, como dice su nombre, de reunificar a la víctima con su familia o en algunos casos con los familiares más cercanos a la misma. Lamentablemente, en algunas oportunidades, si bien la familia se encuentra con vida y fue localizada, ellos no quieren aceptar al niño/ niña o adolescente nuevamente en su seno familiar; esto sucede en algunas situaciones por el miedo que tienen a ser atacados por la víctima, o por ejemplo cuando las niñas regresan embarazadas o con hijos que son consecuencia de los abusos sexuales sufridos durante su reclutamiento en los grupos armados. En estos casos, frente al rechazo de ser recibidos en su hogar, la solución que aporta UNICEF es que sean acogidos por familias dispuestas a darles una adopción, aunque sea temporaria.

- Movilización social con las comunidades $\rightarrow$ el regreso de los niños y niñas a las comunidades a las cuales pertenecen, luego de haber desempeñado la horrible función de ser niño/niña soldado en situaciones de guerra, no es nada fácil. Tampoco es fácil para las comunidades aceptarlos, sobre todo si estas son pequeñas aldeas o pueblos. Es por eso, que uno de los objetivos que UNICEF tiene es el de tratar de garantizar la aceptación como miembro de la sociedad nuevamente a estas víctimas y que les sea ofrecida otra oportunidad. Cabe destacar que muchas veces la aceptación no es fácil, porque los niños y niñas en algunas ocasiones pueden haber sido obligados a realizar atrocidades para con los propios miembros de su comunidad, e inclusive con su propia familia.

Gracias a la puesta en marcha de estos Planes de Acción, entre 2007 y 2017 UNICEF contribuyó a la liberación y reinserción estimativamente de 65.000 menores que se encontraban en situación de soldaditos como consecuencia de haber sido reclutados por distintos grupos armados para tomar parte en las hostilidades (UNICEF, 2017). A su vez, los procedimientos contemplados recientemente son realizados en concordancia con los Principios de París y sus Directrices sobre la protección y reintegración de los niños y niñas vinculados con las fuerzas armadas o con grupos armados, firmado en el año 2007. 
Por último, uno de los hitos dentro del compromiso internacional por parte de Naciones Unidas para poner fin a esta problemática, también se puede evidenciar en el año 2015 cuando se adoptaron los Objetivos de Desarrollo Sostenible para el 2030, ya que en el punto 8.7 hace referencia a la situación de los niños soldados:

Adoptar medidas inmediatas y eficaces para erradicar el trabajo forzoso, poner fin a las formas contemporáneas de esclavitud y la trata de personas y asegurar la prohibición y eliminación de las peores formas de trabajo infantil, incluidos el reclutamiento y la utilización de niños soldados, y, de aquí a 2025, poner fin al trabajo infantil en todas sus formas (Naciones Unidas, 2020).

\section{Niños soldados en los conflictos de Sudán del Sur, República Democrática del Congo y Siria}

Si bien sólo se han elegido 3 países en donde el reclutamiento de niños y niñas para sus conflictos armados es algo persistente, tanto por los grupos oficiales gubernamentales, como por los subversivos, según las cifras que aportó Naciones Unidas, se estima que 20 países alistan a menores en sus filas de combate. (UNICEF, 2020).

La semejanza entre estos 3 países radica que los conflictos comienzan con el detonar de alguna situación de índole política que arraiga la intención de apropiación de territorio. Además, la injusticia social y las desigualdades priman por sobre todas las cosas en estos casos elegidos. Tal como se hizo mención, otro aspecto en común es el reclutamiento de menores tanto por grupos armados oficiales y por no gubernamentales, realizando claras violaciones al Derecho Internacional Público, en especial a aquellos instrumentos a los cuales se encuentran adheridos.

\section{El caso de Siria}

El conflicto de la Primavera Árabe en Siria tiene su origen en el año 2011, cuando los ciudadanos realizan un levantamiento pacífico contra el presidente sirio Bashar Al Asad quien, desde el año 2000, ejerce la presidencia, habiendo sucedido a su padre quien había gobernado por casi 30 años (BBC Mundo, 2018).

Estos levantamientos fueron interpretados como protestas prodemocráticas, dado que, entre sus principales críticas, se encontraban la falta de libertad política, la represión del gobierno, el desempleo, la corrupción, la pobreza y violación repetida a los derechos humanos. Adicionalmente, la principal petición de los mismos era la renuncia del presidente sirio. 
A medida que incrementaron las protestas en diferentes ciudades, fueron surgiendo distintas brigadas y grupos de rebeldes para combatir a las fuerzas del gobierno que reprimía los levantamientos en forma violenta. Un ejemplo de estos grupos es el Ejército Sirio Libre, creado por militares desertores del gobierno que se auto imponen el deber y la función de "proteger a los ciudadanos" (Martin Garcia, 2015, p.2).

Paralelamente, dentro de esta guerra civil que se inició dentro de Siria, comenzó otra guerra encabezada por grupos islamistas y yihadistas (conocidos como Estado Islámico) y el frente Al Nusra (grupo afiliado a Al Qaeda hasta el año 2016) que tenían como fin imponer a los ciudadanos sirios la versión extremista de la Sharía, es decir de la ley islámica. Así es como Siria se transformó en el escenario para lo que se puede interpretar como una guerra dentro de otra guerra (BBC Mundo, 2018).

El autoproclamado Estado Islámico comenzó a atacar a ambos grupos por igual, es decir al bando rebelde, como por ejemplo el Ejército Sirio libre, y al Ejército del régimen del presidente Al-Asad, para poder lograr su cometido de crear un Califato (Martin Garcia, 2015, p5).

El Estado Islámico, conocido a su vez como DAESH, dentro del territorio sirio, violó la Convención sobre los Derechos del Niño (ratificada el 15 de julio de 1993) y sus Protocolos Facultativos (Siria adhirió a los mismos el 17 de octubre del 2003) al reclutar niñas y niños en sus filas combatientes (United Nations, 2020).

Se estima que aproximadamente, hoy en día, hay 1100 niñas y niños reclutados (Syrian Observatory for Human Rights, 2017). Estos son llamados los "cachorros de león del califato", y son entrenados en escuelas de la milicia de DAESH, donde se los adoctrina desde pequeños con propaganda yihadista. Cabe destacar que hay menores de todas las edades, ya que es posible encontrar a niños y niñas de 10 o 12 años empuñando un arma, el caso más joven encontrado es el de un niño de 5 años. A su vez, reciben instrucciones de cómo usar armamentos militares, les enseñan tácticas y les otorgan clases de Corán (Clarín Mundo, 2016).

Estos "cachorros del califato" son la amenaza que la organización prepara para el futuro, entrenan y adoctrinan a niñas y niños para que en los próximos años sean los que lleven a cabo el objetivo último de formar el califato a nivel, cómo se explica a continuación:

...incluir niños entre sus filas permite a DAESH crear lealtades a largo plazo y perpetuar así su régimen de terror en el tiempo. En ocasiones, los incentivos para crear a partir de los niños una cantera de combatientes 
adheridos a su ideología son mayores que la de reclutar combatientes adultos en otros países (González, 2016, p.1).

Los menores son frecuentemente utilizados para cumplir con diferentes funciones dentro del grupo terrorista, como, por ejemplo, son enviados a participar en primera línea de combate, o sirven de espías, también de francotiradores, torturadores y hasta los obligan a inmolarse. Estos niños y niñas son adoctrinados y preparados para pelear en una guerra civil, obligados a participar en un conflicto propio del mundo de los adultos poniendo en jaque el futuro del mismísimo país. La situación siria genera una gran preocupación a nivel internacional, y diversos organismos y organizaciones internacionales están trabajando para poder revertir, sobre todo, el reclutamiento de niñas y niños soldados.

El 29 de junio del 2019, casi una década después de iniciarse los conflictos, en Siria se firmó el primer Plan de Acción entre Naciones Unidas y las Fuerzas Democráticas Sirias (alianza entre diferentes grupos armados que luchan contra el Estado Islámico). Estas últimas acordaron ponerle fin al reclutamiento de menores en sus filas, y a desmovilizar a aquellos que continúan siendo partícipes del conflicto. Esto significa un gran avance para la comunidad internacional, ya que, por primera vez, desde que comenzó la guerra, se estipula y acuerda un plan internacional para hacerle frente a dicha problemática (Noticias ONU, 2019, p.1).

Es importante destacar que el país ratificó la Convención sobre los Derechos del Niño el 15 de julio de 1993, el Protocolo I Adicional a Ginebra el 14 de noviembre de 1983, firmó el Estatuto de Roma el 29 de noviembre del año 2000. En cuanto al Protocolo Adicional a la Convención sobre los Derechos del niño que trata sobre los conflictos armados, se adhirió al mismo el 17 de octubre del año 2003. El Convenio 182 de la OIT también se encuentra vigente en el país desde el 22 de mayo del año 2003 (Coalition for the International Criminal Court, 2020; United Nations, 2020; International Committee of the Red Cross, 2020 e International Labour Organization, 2017).

\section{República Democrática del Congo}

El origen de este conflicto se remonta a la guerra civil de 1998, en la que, al menos 30.000 niños y niñas participaron como soldados. En ese mismo año el país consiguió salir de una dictadura para pasar a convertirse en un prototipo de "Estado fallido", adjetivo utilizado en relaciones internacionales para clasificar a aquellos países que han sido un fracaso en lo social, político y económico, y que han fallado en la garantía de servicios básico, es decir con un gobierno débil e ineficaz (Amnistía Internacional España, 2020). 
Entre los años 1998-2002 el país estuvo gobernado por un gobierno de transición, durante el cual, el Congo se ha transformado en un Estado en conflicto, con un entramado de guerrillas, milicias y fuerzas rebeldes ${ }^{5}$. Entre las mismas se encuentran, la Unión de los Patriotas Congoleños (UPC), la Fuerza de Resistencia Patriótica de Ituri (FRPI), los grupos armados Mai-Mai (milicias locales y comunitarias), las Fuerzas Combatientes Abacunguzi (FOCA), la Unión Patriota para la Defensa de los Inocentes (UPDI), las Fuerzas Armadas Nacionales de la República Democrática del Congo (FARD) (La Vanguardia, 2018) ${ }^{6}$.

Un aspecto que estos grupos tienen en común es el reclutamiento de niños y niñas en conflictos armados. Se estima que alrededor del 30\% de los participantes de estos grupos armados son menores de edad (Oficina del Representante Especial del Secretario General para los niños y los conflictos armados, 2016).

Los grupos irregulares que se encuentran no son los únicos responsables de su reclutamiento, debido a que las Fuerzas Armadas nacionales continúan con dicha atrocidad, pese a que "habían puesto fin oficialmente al reclutamiento infantil en 2004" (Amnistía Internacional España, 2020).

En dicho año, Joseph Kabila, se comprometió a que en el país no haya más reclutamiento de niños y niñas. Conforme a tal objetivo, adoptó una política nacional de desarme, desmovilización y reintegración de menores de edad soldados. Siguiendo con esta línea, aprobó un marco normativo por medio del cual se disponía a evitar el reclutamiento de menores de 18 años para integrar fuerzas o grupos armados. Prueba de ello es la Constitución del año 2006, en donde se dispone lo siguiente:

...Prohíbe el empleo de niños en las actividades de las fuerzas armadas, y la Ley $\mathrm{N}$ o 04/23 de Diciembre de 2004 prohíbe el reclutamiento de personas menores de 18 años en las fuerzas armadas nacionales. El Código de Protección de la Infancia de Enero de 2009 también prohíbe

\footnotetext{
${ }^{5}$ En el año 2003 hasta el 2019 ejerció el mandato Joseph Kabila, cuyo mandato ha sido totalmente débil, su gobierno no controla todo el territorio congoleño, y las fuerzas armadas del país distan mucho de la noción clásica de lo que se conoce como ejército, ya que son unas fuerzas corruptas, con insuficiente adiestramiento y disciplina. Desde enero del presente año Félix Tshisekedi es quien ejerce la presidencia.

${ }^{6}$ En este territorio también operan fuerzas de los países vecinos:

En la extensa frontera oriental que separa al país de Uganda, Ruanda y Burundi, opera cerca de una decena de grupos armados irregulares: guerrillas tutsi del temido M23, sus rivales hutu del Frente Democrático para la Liberación de Ruanda (FDLR), varias milicias locales, como los Mai-Mai y el Frente de Defensa del Congo (FDC); así como grupos armados burundeses y ugandeses, entre los que figura el Ejército de Resistencia del Señor, liderado por Joseph Kony, de reciente notoriedad por sus prácticas brutales y crímenes de guerra (Galarza, 2012, p.1)
} 
el reclutamiento y la utilización de niños en grupos armados, y define la responsabilidad del gobierno para desmovilizar la reintegración de los niños soldados (Fustino de Miranda, 2013, p18).

Además, estableció diálogo con los distintos grupos armados y de esta forma logró liberar a cinco mil menores que había sido reclutados para cumplir la tarea de soldados. Dentro de este marco de diálogo, dichos grupos se comprometieron, no solo a la desmovilización, sino también a la reintegración de estas niñas y estos niños, teniendo como resultado 700 menores reinsertados en la sociedad (Arellano, 2008).

Siguiendo la línea de estas iniciativas, años después, en el 2012, el gobierno de Kabila se comprometió con Naciones Unidas a implementar un Plan de Acción, en el cual se estipulaba, entre otras cosas, finalizar con el reclutamiento de niñas y niños soldados.

De todas maneras, un año después del compromiso, la misión de Naciones Unidas en la República Democrática del Congo afirmó que los reclutamientos de menores de edad continuaron, resultando débil el Plan de Acción.

Frente a esta situación, Joseph Kabila, retomó su compromiso de aplicar el Plan de Acción firmado en el año 2012, y junto con el Ministro de Defensa del país, establecieron una hoja de ruta en la cual figuraban los asuntos pendientes de dicho plan, y de este modo poder completar el mismo.

Continuando con los compromisos pactados, Las Fuerzas Armada de la República Democrática del Congo, durante el transcurso del 2015, "entregaron a las Naciones Unidas a 139 niños y niñas anteriormente asociados a grupos armados". A su vez, en un intento de que los culpables de violar los derechos de la infancia rindan cuenta, "fueron detenidas al menos 68 personas, entre ellas oficiales de alto rango de las FARDC y la Policía Nacional Congolesa”. Actualmente, el Plan de Acción continúa vigente (Oficina del Representante Especial del Secretario General para los Niños y los Conflictos Armados, 2016).

Asimismo, la acción de la comunidad internacional en República Democrática del Congo se puede plasmar también en el caso de Thomas Lubanga, ex jefe del movimiento de rebeldes llamado Unión de los Patriotas Congoleños (UPC), creado en el año 2002.

Esta persona fue el primer condenado por la Corte Penal Internacional (C.P.I.) y debe cumplir una pena de 14 años en prisión por los delitos de crímenes de guerra y reclutamiento de niños y niñas en conflictos armados que llevó adelante en sus años como jefe del movimiento UPC. Otro de los casos, es el del ex vicepresidente congoleño, Jean-Pierre Bemba, condenado en junio del año 2016 a 18 años de 
prisión, por los crímenes contra la humanidad cometido por sus milicias en sus años de mandato, entre lo que se destacan el reclutamiento de menores.

Por último, desde el punto de vista normativo, es pertinente destacar que la República Democrática del Congo ratificó los siguientes instrumentos: la Convención sobre los Derechos del Niño el día 27 de septiembre de 1990, el Protocolo Adicional respecto a los conflictos armados el 11 de noviembre del año 2001, el Estatuto de Roma el 11 de abril del 2002, los Protocolos Adicionales a Ginebra (I y II) el 3 de junio de 1982 y el 12 de diciembre del 2002; a su vez, en dicho país se encuentra en vigor el Convenio 182 de la OIT desde el 20 de junio del año 2001 (Coalition for the International Criminal Court, 2020; United Nations, 2020; International Committee of the Red Cross, 2020 e International Labour Organization, 2017).

\section{Sudán del Sur}

El inicio del conflicto en Sudán del Sur fue en el año 2013, dos años después de que lograra su independencia de Sudán del Norte, como consecuencia de una guerra civil en donde la parte Sur, cristiana en su mayoría, se enfrentó a la parte Norte, musulmana mayoritariamente. Luego de décadas de enfrentamientos y de conseguir un gobierno propio a nivel regional, Sudán del Sur se independizó con el acuerdo de paz del día 9 de julio del año 2011 (BBC News, 2016).

El nuevo gobierno se encontraba formado por un presidente de la etnia Dinka y por un vicepresidente, de la etnia Nuer. La guerra civil comienza cuando el presidente expulsa al vicepresidente (con acusaciones de querer llevar adelante un Golpe de Estado) y a todos los funcionarios públicos de la etnia Nuer del gobierno, desatando así un conflicto étnico (Ayuso, 2015, p.1).

Dos años después del nacimiento del Estado-nación de Sudán del Sur, se inicia un conflicto político-étnico que genera alarma a nivel mundial por la grave situación humanitaria en la que se encuentran sus habitantes. En esta guerra civil se violan constantemente los derechos humanos, teniendo como consecuencias, muertos, una nación con hambruna, desplazados, refugiados.

Con respecto a la captación de menores de edad para integrar estos grupos armados, tema de la presente investigación, se da por parte de los dos bandos, es decir que tanto el ejército del presidente de Sudán del Sur, como el grupo de rebeldes, reclutan niños y niñas para servir como soldados. Según cifras que otorga UNICEF, se estima que aproximadamente 16.000 niños y niñas han sido reclutados para participar en la guerra civil sudanesa. Como argumenta el director africano de Human Rights Watch, "los comandantes constante y brutalmente reclutan y utilizan 
niños para la guerra interna en total oposición a lo que es la ley de Sudán y la propia seguridad de los menores" (Bekele en Human Rights Watch, 2015, p.2).

Pese a ser culpable de gran parte del reclutamiento de niños y niñas, el gobierno de Sudán del Sur en el año 2014 se unió a la campaña de magnitud mundial "Child, not soldiers" emitida por Naciones Unidas, y lanzó un comunicado por radio para informar a la población que iba a haber sanciones para quienes recluten niños y niñas en sus filas.

No obstante, frecuentemente, los líderes de distintos grupos insurgentes lograron obtener de facto la amnistía por parte del gobierno de turno, una vez llegado el acuerdo de paz, y así lograban despojarse de toda sanción. Un ejemplo de esto es el caso del líder rebelde David Yau Yau, responsable del reclutamiento de aproximadamente 1700 menores (Human Rights Watch, 2015).

Para hacer frente a esta compleja situación, la comunidad internacional ha tomado cartas en el asunto, y a raíz de ello, en marzo del 2015, la Autoridad Intergubernamental para el Desarrollo (IGAD) junto a la Unión Africana, se encargaron de la mediación para un arreglo pacífico de este conflicto.

Fue en ese mismo año que "UNICEF supervisó la liberación de 1.775 ex niños soldado en lo que fue una de las mayores desmovilizaciones de menores que se han producido" (Europa Press, 2016).

Sin embargo, este gran logro fue opacado y debilitado por el resurgimiento de la guerra civil al interior del país. La escalada del conflicto continuó aumentando, a tal punto que en mayo del mismo año se conoció sobre el asesinato de 129 niños y niñas soldados por parte de los bandos en conflictos (Ministerio para Europa y de Asuntos Exteriores, 2015).

Afortunadamente, Naciones Unidas junto a UNICEF, ha logrado establecer un Plan de Acción. El mismo fue firmado por el gobierno de Sudán del Sur y por el coordinador residente y coordinador humanitario de UNAMID y UNICEF. En dicho plan, se propone una hoja de ruta para lograr la protección integral de los derechos de la infancia en Sudán del Sur, específicamente, se propone evitar el reclutamiento de menores de edad en conflictos armados, junto con la liberación de quienes se encuentran en los bandos en conflicto, con la posterior rehabilitación y reinserción en la sociedad.

Pese al Plan de Acción establecido, el reclutamiento de niñas y niños soldados en este país continúa siendo una preocupación para la comunidad internacional, ya que, si bien han logrado desmovilizar cantidades de menores, las cifras del reclutamiento siguen siendo alarmantes.

Por último, resulta importante destacar que, Sudán del Sur adhirió a la Convención Sobre los Derechos del Niño el 23 de julio del año 2015. A su vez, se encuentra en 
vigor el Convenio 187 de la OIT desde el 29 de abril del 2012, y en cuanto a los Protocolos (I y II) Adicionales a Ginebra, ha ratificado los mismos el día 25 de enero del año 2013, en conjunto con la Convención de Ginebra (Coalition for the International Criminal Court, 2020; United Nations, 2020; International Committee of the Red Cross, 2020; International Labour Organization, 2017).

\section{Conclusión}

Tal como se expuso en el presente trabajo, el reclutamiento de niñas y niños en conflictos armados es una problemática que persiste actualmente a nivel mundial. Empero, a fin de hacer frente a dicha situación, la comunidad internacional en su conjunto ha realizado vastos esfuerzos para, no solo visibilizar el fenómeno de menores participando en hostilidades, sino también para encontrar una solución y poder llegar a su fin. Por tal motivo, resulta imperioso resaltar las tareas desarrolladas tanto por el Derecho Internacional Público, como por Naciones Unidas junto a la agencia UNICEF.

Por un lado, en cuanto a la labor de la normativa internacional, los esfuerzos realizados en pos de brindar la protección correspondiente los derechos de niños y niñas en situaciones de conflictos armados, se pueden materializar en los diferentes Protocolos, Convenciones y Estatutos implementados desde la finalización de la Segunda Guerra Mundial. La evolución de los mismos, tal como se lo ha expuesto en el presente trabajo, denota la voluntad de la comunidad internacional en poner un fin a esta problemática, así como también de proteger a los derechos de la infancia.

A su vez, se destaca que el Derecho Internacional con sus instrumentos no solo buscó proteger a los niños y las niñas ante situación de hostilidades, sino que también identificar a los culpables de cometer dicha atrocidad, a fin de que sea juzgado y sentenciado por llevar adelante tales crímenes y vulneraciones del derecho de la infancia. Ejemplo claro de ello se puede observar en uno de los casos presentados.

Por otro lado, en cuanto a la labor desarrollada tanto por Naciones Unidas como UNICEF, desde la presentación del Informe Machel en 1996, se han realizado notorios esfuerzos para informar a la comunidad internacional acerca las dimensiones reales de lo que implica el reclutamiento de niños y niñas en conflictos armados. A partir de esto, una vez situada dicha problemática en la agenda internacional, los trabajos realizados y las resoluciones aprobadas por el Consejo de Seguridad han ocupado un lugar de atención primordial dentro de dicho Organismo Internacional. Diferentes Planes de Acción coordinados con UNICEF fueron sumamente satisfactorios para la liberación y reinserción de niños y niñas soldados. 
Por último, teniendo en cuenta los diferentes casos de estudio presentados, se puede afirmar que tanto el Derecho Internacional como Naciones Unidas junto a UNICEF, han desempeñado un rol fundamental en la problemática de menores participando en las hostilidades.

Por un lado, al ser los 3 países firmantes de los diferentes instrumentos del Derecho, la presión internacional ejercida en pos de su debido cumplimiento fue notoria, y, en el caso de República Democrática del Congo, la Corte Penal Internacional sentenció a los culpables de violar a las diferentes normativas reclutando a menores en sus filas, entre otros crímenes. En cuanto al rol de UNICEF junto a Naciones Unidas, en los 3 países se puede dar cuenta que se han implementado diferentes Planes de Acción a fin de eliminar el reclutamiento de niños y niñas soldados, y colaborar en la reinserción de aquellos menores liberados de su participación en hostilidades.

\section{Referencias bibliográficas}

ACNUDH. (Marzo de 2020). Oficina del Alto Comisionado para los Derechos Humanos. Obtenido de Oficina del Alto Comisionado para los Derechos Humanos: https://www.ohchr.org/SP/ProfessionalInterest/Pages/OPACCRC.aspx

ACNUR. (Marzo de 2018). UNHCR ACNUR. Obtenido de UNHCR ACNUR: https://www.acnur.org/fileadmin/Documentos/BDL/2008/6260.pdf?view=1

Amnistía Internacional España. (2020). Amnistía Internacional. Obtenido de Amnistía Internacional: https://www.es.amnesty.org/actua/acciones/republica-democraticadel-congo-ninos-y-ninas-entre-fuegos-cruzados/

Arellano V., M. (2008). Uso y participación de niños en conflictos armados. Granada: Editorial de la Universidad de Granada.

Ayuso, J. (15 de Agosto de 2015). Sudán del Sur, un país derrotado. El País, págs. 16.

BBC Mundo. (15 de Abril de 2018). BBC News. Obtenido de BBC News: https://www.bbc.com/mundo/noticias-internacional-37451282

BBC News. (11 de Julio de 2016). BBC Mundo . Obtenido de BBC Mundo: https://www.bbc.com/mundo/noticias-internacional-36768560

Clarín Mundo. (22 de Agosto de 2016). Niños de la guerra: Los cachorros del Califato: Así entrena el ISIS a los chicos. Clarín, págs. 1-3. 
Comité Internacional de la Cruz Roja. (Marzo de 2020). Comité Internacional de la Cruz Roja. Obtenido de Comité Internacional de la Cruz Roja: https://www.icrc.org/es/document/protocolo-i-adicional-convenios-ginebra1949-proteccion-victimas-conflictos-armados-internacionales-1977

Europa Press. (2016). UNICEF llama a acabar con el reclutamiento de niños soldados en Sudán del Sur. Europa Press, 1-2.

Fondo de las Naciones Unidas para la Infancia (UNICEF). (2009). EXAMEN ESTRATÉGICO 10 AÑOS DESPUÉS DEL INFORME MACHEL, LA INFANCIA Y LOS CONFLICTOS EN UN MUNDO EN TRANSFORMACIÓN. New York: UNICEF.

Galarza, R. (30 de Noviembre de 2012). El conflicto en Congo. El Observador, págs. $1-3$.

González, I. (2016). Niños soldados: del Congo a Siria. Estudios de politica exterior, 2.

Hinestroza-Arenas, V. (2008). Reclutamiento de niños y niñas: fenómeno invisibilizado, crimen manifiesto. OASIS, 45-60.

Human Rights Watch. (14 de Diciembre de 2015). Human Rights Watch. Obtenido de Human Rights Watch: https://www.hrw.org/news/2015/12/14/south-sudanterrifying-lives-child-soldiers

Humanium. (19 de Marzo de 2020). Humanium. Obtenido de Humanium: https://www.humanium.org/es/signatarios-convencion/

International Committee of the Red Cross. (2020). International Committee of the Red Cross. Obtenido de International Committee of the Red Cross: https://ihldatabases.icrc.org/applic/ihl/ihl.nsf/States.xsp?xp_viewStates=XPages_NORMStat esParties\&xp_treatySelected $=470$

International Criminal Court. (2020). International Criminal Court. Obtenido de International Criminal Court: http://www.iccnow.org/documents/Signatories_RomeStatute_sp.pdf

International Labour Organization . (2017). International Labour Organization . Obtenido de International Labour Organization : https://www.ilo.org/dyn/normlex/es/f?p=NORMLEXPUB:11300:0::NO::P11300_ INSTRUMENT_ID:312327

International Labour Organization. (2017). Organización Internacional del Trabajo. Obtenido de Organización Internacional del Trabajo: https://www.ilo.org/dyn/normlex/es/f?p=NORMLEXPUB:12100:0::NO::P12100_ ILO_CODE:C182 
La Vanguardia. (19 de Diciembre de 2018). Datos básicos y evolución política de la República Democrática del Congo. La Vanguardia, págs. 1-3.

Martin García, M. A. (16 de Septiembre de 2015). Senderos de la Historia . Obtenido de Senderos de la Hisotoria: https://senderosdelahistoria.wordpress.com/2015/09/16/las-causas-de-la-guerracivil-siria/

Ministerio para Europa y de Asuntos Exteriores . (17 de Febrero de 2015). France Diplomatie. Obtenido de France Diplomatie: https://www.diplomatie.gouv.fr/es/fichas-de-paises/sudan-delsur/noticias/article/sudan-del-sur-enrolamiento-de

Naciones Unidas . (2020). Objetivos de Desarrollo Sostenible. Obtenido de Objetivos de Desarrollo Sostenible: https://www.un.org/sustainabledevelopment/es/economicgrowth/

Naciones Unidas. (20 de Abril de 2016). Oficina del Representante Espacial del Secretario General para los Niños y los Conflictos Armados. Obtenido de Oficina del Representante Espacial del Secretario General para los Niños y los Conflictos Armados: https://childrenandarmedconflict.un.org/es/republica-democratica-delcongo/

Naciones Unidas. (20 de Abril de 2016). Oficina del Representante Especial del Secretario General para los niños y los conflictos armados. Obtenido de Oficina del Representante Especial del Secretario General para los niños y los conflictos armados: https://childrenandarmedconflict.un.org/es/republica-democratica-delcongo/

Naciones Unidas. (2019 de Junio de 2019). Noticias ONU. Obtenido de Noticias ONU: https://news.un.org/es/story/2019/07/1458682

Naciones Unidas. (2020). Oficina del Representante Especial del Secretario General para los niños y los conflictos armados. Obtenido de Oficina del Representante Especial del Secretario General para los niños y los conflictos armados: https://childrenandarmedconflict.un.org/es/planes-de-accion/

Naciones Unidas. (2020). Oficina del Representante Especial del Secretario General para los niños y los conflictos armados. Obtenido de Oficina del Representante Especial del Secretario General para los niños y los conflictos armados: https://childrenandarmedconflict.un.org/es/nuestro-trabajo/acerca-denosotros/historia/ 
Naciones Unidas. (2020). Oficina del Representante Especial del Secretario General para los Niños y los Conflictos Armados. Obtenido de Oficina del Representante Especial del Secretario General para los Niños y los Conflictos Armados: https://childrenandarmedconflict.un.org/es/nadie-menor-de-18/

Naciones Unidas. (2020). Oficina del Representante Especial del Secretario General para los Niños y los Conflictos Armados. Obtenido de Oficina del Representante Especial del Secretario General para los Niños y los Conflictos Armados: https://childrenandarmedconflict.un.org/es/nuestro-trabajo/acerca-denosotros/historia/

Platnner, D. (1984). La protección a los niños en el derecho internacional humanitario. Gineba: Comité internacional de la Cruz Roja.

UNHCR ACNUR. (s.f de s.f de 2017). UNHCR ACNUR Agencia de la ONU para los refugiados. Obtenido de UNHCR ACNUR Agencia de la ONU para los refugiados: http://www.acnur.org/t3/fileadmin/Documentos/BDL/2010/8025.pdf?view=1

UNICEF. (Febrero de 2007). UNICEF. Obtenido de UNICEF: https://www.unicef.org/protection/Paris_Principles_SP.pdf

UNICEF. (21 de Febrero de 2017). UNICEF. Obtenido de UNICEF: https://www.unicef.org/lac/comunicados-prensa/al-menos-65000-ni\%C3\%B1oshan-sido-liberados-de-fuerzas-y-grupos-armados-en-los

UNICEF. (20 de Marzo de 2020). UNICEF. Obtenido de UNICEF: https://www.unicef.es/noticia/ninos-y-ninas-en-armas

UNICEF. (2020). UNICEF. Obtenido de UNICEF: https://www.unicef.org/spanish/protection/57929_57997.html

UNICEF Comité Español. (Mayo de 2015). UNICEF. Obtenido de UNICEF: https://www.unicef.es/sites/unicef.es/files/comunicacion/ConvencionsobrelosDer echosdelNino.pdf

UNICEF España. (2020). UNICEF. Obtenido de UNICEF: https://www.unicef.es/prensa/el-informe-machel-destaca-que-el-impacto-de-laguerra-en-la-infancia-es-mas-brutal-que-nunca

UNICEF España. (2020). UNICEF. Obtenido de UNICEF: https://www.unicef.es/ninos-soldado

United Nations. (2020). Naciones Unidas. Obtenido de Naciones Unidas: https://www.un.org/spanish/law/icc/statute/spanish/rome_statute(s).pdf 
United Nations. (2020). United Nations Treaty Collection. Obtenido de United Nations Treaty Collection: https://treaties.un.org/Pages/ViewDetails.aspx?src=TREATY\&mtdsg_no=IV$11 \&$ chapter $=4 \&$ clang $=\_$en 